\title{
Resenha Entre Estruturas e Agentes: Recente contribuição para a discussão acerca de Práticas de Consumo na
}

\section{Sociedade Contemporânea. \\ Vanessa Ionara dos Santos Rodrigues ${ }^{1}$}

${ }^{1}$ Graduanda em Ciências Sociais pela Universidade Federal do Recôncavo da Bahia. Integra o Grupo de Pesquisa ECCOS (Corpo, Socialização e Expressões Culturais), da Universidade Federa do Recôncavo da Bahia. Atualmente desenvolve a pesquisa FAPESB "A Face dos Cheiros: publicidade e indústria de perfumaria”. E-mail: vanessaionara@hotmail.

com.

\section{CRUZ, Isabel Maria Fernandes da Silva. Entre Estruturas e Agentes: padrões e práticas de consumo em Por- tugal Continental. Porto, Edições Afrontamento, 2013.}

Entre Estruturas e Agentes: Padrões e Práticas de Consumo em Portugal Continental, de Isabel Maria Fernandes da Silva Cruz, foi o trabalho desenvolvido para obtenção do grau de Doutora em Sociologia pela Faculdade de Letras da Universidade do Porto, que deu origem à recente publicação de um livro de mesma intitulação, publicado por Edições Afrontamento, em Porto, no ano de 2013. Investigadora integrada à UP, a autora interessa-se pelas áreas de Sociologia do Consumo e Pobreza e exclusão social.

O objeto de estudo consiste nos padrões e nas práticas de consumo em Portugal Continental. As discussões sobre Práticas de Consumo são tidas como seminais nas Sociedades Contemporâneas, que são sociedades de consumo.
Argumenta-se que as mudanças no domínio do simbólico encontram-se, também, associadas ao desenvolvimento socioeconômico. Ressalta-se que a era do consumo corresponde ao ciclo que tem início nos benefícios do industrialismo, na simplicidade e na funcionalidade, indo do funcionalismo ao pós-modernismo. O papel e a influência da pertença social do indivíduo sobre as suas escolhas e práticas de consumo são tidos como uma questão central na sociologia do consumo.

Sua tese divide-se em três partes principais: a primeira apresenta revisão de algumas das principais perspectivas teóricas surgidas, em sua maioria, a partir da segunda metade do século XX que colaboraram para a sociologia do consumo, além do uso da Teoria Social para analisar as prá- 
ticas de consumo em sua diversidade de perspectivas. Discute conceitos como o de habitus, ator plural e reflexividade, contendo contribuições do teórico francês Pierre Bourdieu (1979), de Lévi-Strauss (1974), Neef (1991), Giddens (1996), Heilbrunn (2005), Alonso (2005), Thorstein Veblen (1970), Bauman (2008), Weber (1983), entre outros. Cruz cita cento e treze referências bibliográficas que a embasaram e auxiliaram na construção de sua obra. Na segunda parte, aponta de maneira relevante e detalhada informações a respeito das metodologias das quais se utilizou, embasada principalmente por Lahire (2004), apresenta os dados, além das análises dos mecanismos qualitativos da pesquisa. A terceira trata-se das conclusões.

Coloca o consumo enquanto prática relacional (Relação ator/contextos e espaços sociais, ator/outros atores, ator/ sua trajetória, ator/objetos de consumo e significado simbólico) situada no tempo e no espaço, se propondo a realizar uma análise pluriperspectivada do consumo, fenômeno que conserva uma espécie de dinâmica na memória coletiva. Ressalta também que as fronteiras do consumo remetem para as fronteiras socioculturais, de modo que estruturas mentais induziriam práticas sociais que trabalham como verdadeiros reguladores na medida em que inscrevem o indivíduo na cultura ou dela o excluem caso ele transgrida as prescrições implícitas do sistema cultural. As sociedades atuais, onde os laços sociais são progressivamente distendidos, dão margem a substituição dos mesmos por objetos de consumo (por meio de reapropriações individuais e simbólicas). A partir de Csikszentmihalyi e Rochberg-Halton (1981), cita que os bens simbólicos conferem sentido e continuidade à vida pessoal, desenvolvendo quatro papéis fundamentais: o de mediadores de conflitos internos; exprimem qualidades pessoais; indicam status e promovem a integração social. Critica algumas perspectivas da economia, que ao utilizar em suas análises apenas os conceitos de necessidade e utilidade, desconsideram o desejo, que corresponderia ao principal motor do consumo Baseada em Neef (1991), traz a ideia de que nas sociedades ocidentais o consumo está diretamente conexo à satisfação de necessidades humanas relacionadas à afetividade, participação, compreensão, ociosidade e identidade. Atenta para o fato de que as práticas de consumo não são aleatórias, assim como é necessário admitir que os consumidores são seres reais, dotados de uma história, de afetos, de desejos, de constrangimentos econômicos, temporais, entre outros fatores.

A partir de contribuições de Halbwachs (1913), para quem as relações sociais determinam as necessidades, as práticas sociais e, consequentemente, a estrutura de consumo dos diferentes grupos sociais, de modo que o consumo explica-se pelo nível de vida, Cruz argumenta que o consumo é uma construção social e revela a representação coletiva que a sociedade faz de si. Em função do lugar que ocupam, a natureza e a quantidade de necessidades individuais são determinados 
pela sociedade. Traz também Baudrillard (1981), que defende que os objetos constituem sistemas de significados, transmitindo um patrimônio ideológico, de valores, de gestos e de rituais, de modo que esta capacidade de integrar dimensões psíquicas, ideológicas e comportamentais é explicadora do poder dos bens de consumo em relação à sensibilidade e à sociabilidade. O conceito de consumo sustentável também é discutido, conceito fundado na relação entre consumo e bem-estar, em relação ao qual se pretende possibilitar a criação de uma estratégia para produzir significado pessoal e cultural que seja mais ecológica, reduzindo os impactos ambientais, e não desprezando, é claro, os condicionamentos do contexto social e cultural na definição e no constrangimento da escolha individual, sentido que suscita de alguns autores a ênfase em intervenções políticas que fomentariam e apoiariam determinados comportamentos morais e sociais.

Sobre Pierre Bourdieu, destaca sua obra La Distinction (1979), onde Bourdieu analisa, através de materiais empíricos, a centralidade das práticas de consumo na criação e manutenção de relações sociais de dominação e de submissão, centrando-se nos mecanismos de reprodução social, salientando o modo como as sociedades mantêm as estruturas de ordem entre os grupos sociais e as relações de poder de um grupo face a outros. Sobre o gosto, Bourdieu afirma que o mesmo depende da herança sociocultural interiorizada pelo indivíduo, constituindo um mecanismo central na organi- zação e na distribuição de recursos simbólicos e desempenhando um papel crucial na reprodução social. Suas afirmações associam o desenvolvimento da cultura de consumo à estilização e à estetização das práticas. Em sua proposta, a identidade social se define e afirma na diferença através das práticas de classificação. Para Bourdieu, é por meio de uma lógica da prática que os indivíduos se esforçam por melhorar a sua posição no espaço das posições sociais, manipulando bens e representações culturais da sua posição no campo social. Trazendo Barbosa (2008), que em seu livro Sociedade de Consumo apresenta variados temas associados aos conceitos de sociedade e cultura de consumo a partir de contributos de diversos autores, Cruz apresenta algumas das críticas tecidas a Bourdieu: critica Bourdieu por considerar que, na sociedade de consumo contemporânea, a posição dos bens é instável e a sua duração variável.

Douglas e Isherwood (2004) colocam o consumo para além do puro comércio e integram sempre uma dimensão cultural e econômica. O que se defende é uma relação de determinação entre a utilidade de um bem e um quadro cultural, onde o consumo consiste em um sistema de trocas que posiciona os indivíduos através do status e de papéis codificados. Deste modo, importa entender de que maneira o objeto consumido é suscetível de ser um meio de comunicação que induz lógicas de identidade, de inclusão e de exclusão. O consumo se torna, então, uma forma aprazível de cumprir as obriga- 
ções sociais. Heilbrunn (2005) critica Douglas e Isherwood, atentando para algumas falhas: os autores não atenderem à relação entre mudança simbólica e desigualdade social, nem à influência que a cultura material pode ter na consolidação da desigualdade social. Além do fato de não levarem em consideração a influência que as estruturas de mediação como a publicidade, a imprensa, entre outros, têm sobre o processo de transferência de sentido, nem o modo como os indivíduos avaliam e são avaliados pelos demais. Apresenta também uma considerável colaboração de Bauman (2008), para quem a sociedade de consumo baseia-se no princípio do prazer, que, por sua vez, encontra-se associado à riqueza que proporciona o prazer imediato e a satisfação instantânea. Bauman argumenta que a virtude essencial de um membro da sociedade de consumo é a sua participação ativa no mercado, de modo que recorrer ao crédito para fazer funcionar a economia corresponde a uma obrigação patriótica e a um hábito interiorizado através do processo de socialização. De maneira sucinta, coloca que a transitoriedade afirma-se como característica e anexa-se aos bens. Traz o conceito de economia do engano para descrever essa sociedade caracterizada por uma economia dos excessos e dos desejos. O autor avalia que a utopia consumista não torna as pessoas mais generosas nem mais empenhadas em se ajudarem umas às outras. Cruz coloca ainda, de maneira breve, algumas das críticas de que as teses de Bauman são objeto.
Em um apanho histórico da sociedade de consumo, ressalta que a industrialização beneficia a maleabilidade e a inovação crescentes, gerando a cultura da novidade e da inovação. Simultaneamente, surgem produtos novos e a uniformização da oferta, que recebem reforços da moda e do marketing, que, por sua vez, incrementam a distinção entre o valor de signo e o valor de uso, associando significados sociais e simbólicos aos objetos, modificando a relação dos consumidores com a mercadoria industrial. Citando novamente Barbosa (2008), argumenta que a característica distintiva da sociedade de consumo é que ela constitui a principal forma de reprodução e de diferenciação social.

Campbell (2000, 2005) traz as noções de que, no contexto do hedonismo moderno, a principal atividade do consumo é a procura do prazer imaginativo associado a um produto, o prazer das experiências autoilusivas construídas a partir de significados associados. Conceitua o desejo, que só pode ser identificado subjetivamente, como um estado difuso de atração por um objeto particular. Para o mesmo, uma prática e uma ideologia marcadamente individualista, o sentimento e a emoção seriam quatro das características centrais do consumismo moderno.

A autora afirma que a sociologia do consumo privilegia a relação entre a utilidade de um bem e o quadro cultural. De modo que o consumo é tanto uma questão de preço, de troca e de relação econômica quanto de sentido, de valor, de comuni- 
cação e de status e de papéis codificados, através dos quais os indivíduos são posicionados na hierarquia social. O valor dos objetos varia a partir de critérios situacionais, de variáveis sociológicas e dos valores de consumo projetados pelo sujeito nos objetos. Por meio dos valores são integradas na análise a dimensão afetiva, a criatividade dos agentes e as representações imaginárias veiculadas pelos bens de consumo. Portanto, o desejo é conceitualizado a partir de processos sociais e psicológicos. O consumo é perspectivado como fundamental forma de reprodução e de comunicação social característica da sociedade de consumo.

No que diz respeito ao diálogo estabelecido na obra com a Teoria Social contemporânea, os referenciais teóricos escolhidos foram a Teoria da Prática de Bourdieu (2002) e os seus prolongamentos críticos, em particular, a tese do ator plural (Lahire, 1998). A afirmação de Bourdieu de que “a prática é a única maneira de compreender a prática” estabelece a base do trabalho de investigação. Sua análise das práticas de consumo situa-se ininterruptamente entre as estruturas e os agentes, e a partir das práticas de consumo, se propõe a analisar a pluralidade do ator social diante destas mesmas práticas, enfatizando a importância de discutir o conceito de habitus. Na perspectiva apresentada, a ação humana não é comandada pela estrutura social nem deriva da livre criatividade dos indivíduos, mas é estruturada e estruturante, o que estabelece uma relação entre habitus e campo (lugar onde as disposições constitutivas do habitus formam-se, operam e adquirem valor). É essa relação prática com os diferentes campos constituinte do habitus que coloca o conhecimento do cotidiano como aspecto central para a sociologia. Os usos do tempo e do espaço pelos agentes sociais são considerados pontos pertinentes na análise das práticas de consumo.

Apresentando algumas outras abordagens, é citada a importância de considerar, na análise das práticas de consumo, a possibilidade de existir uma autonomia relativa da esfera cultural e simbólica, assim como a relação entre as práticas e a produção e a reprodução das estruturas sociais que as determinam. Outro ponto é a reflexividade, posta como uma das características dos sujeitos. A partir de Kaufmann (2001), a hipótese que coloca no centro da construção do $E u$ o processo de exteriorização-objetivação e torna a subjetividade uma parte integrante do mesmo também é considerada. Sobre o ator plural, e contando com as contribuições teóricas de Lahire (1998), identificar a diversidade interna do indivíduo e analisar esta pluralidade do ator por relação aos contextos em que as práticas se desenvolvem também se tornam indispensáveis à pesquisa; assim como a integração da dimensão temporal na análise das práticas de consumo se mostra como de extrema relevância na compreensão das escolhas e dos desejos que lhe subjazem. A integração dessa dimensão temporal reforça a importância de distinguir hábitos corporais e hábitos reflexivos. Admitir que o comportamento social va- 
ria em função do contexto e da pluralidade interna do ator é um outro aspecto. A análise de Isabel Cruz se pretende plural, tensa e reflexiva.

Partindo da discussão sobre habitus e reflexividade, baseada nas teorias e aspectos considerados, destaca alguns pontos pertinentes para a compreensão das práticas de consumo, tais como: considerar que nem sempre o indivíduo consegue identificar uma razão, mesmo que falsa, para o seu comportamento e associar esta identificação à avaliação da responsabilidade moral dos atos; a associação entre situações críticas, que põem em causa a segurança ontológica, e a necessidade de gerir os desejos; identificar o tipo de racionalidade que preside às escolhas do consumidor, num dado contexto; a questão da obrigatoriedade de consumir (ressaltando que esta não pode tornar subalterno o conceito de reflexividade na análise); a possibilidade de testar empiricamente quer o grau de homogeneidade/heterogeneidade do sistema de disposições, quer a existência de uma autonomia relativa da esfera cultural e simbólica; questionar o conceito de cultura proposto por Bourdieu, dando ênfase à necessidade de atender aos contextos em que estas práticas se desenvolvem; considerar o meio social como um nível intermédio entre as práticas e as representações individuais e os sistemas sociais e culturais; considerar o contexto como sendo simultaneamente constrangedor e libertador das práticas; pensar os conceitos de reflexividade, de reconhecimento e de identidade numa relação de proximidade; analisar as estratégias de identificação com o sistema dominante e as estratégias de diferenciação desenvolvidas pelos atores sociais. De maneira sucinta, ancorados nesta diversidade de perspectivas a tese realiza uma análise pluriperspectivada do consumo como prática social, posicionada entre as estruturas e os agentes, através da qual se pretende analisar as limitações e as potencialidades do modelo de análise empregado que agrega algumas das mais significativas contribuições teóricas da Sociologia Contemporânea.

Uma heterodoxia controlada caracteriza o modelo de análise da pesquisa, onde a Teoria da Prática e os seus prolongamentos críticos (especialmente a tese do ator plural) são tomados para aprofundar o conhecimento do consumo enquanto prática social. A fecundidade heurística do modelo provém da sua abertura para acordar novas propostas, assim como do acréscimo resultante de críticas complementares e do controle mútuo, que potencia a sua capacidade analítica. A relação entre o poder / volume e espécie de capitais, o habitus, o campo e a reflexividade, assumem destaque, à medida que a centralidade do consumo no processo de reprodução social e o estabelecimento de relações entre este e a cultura é reconhecida. Reforça a possibilidade de o consumo colaborar com as discussões acerca da natureza da realidade.

A segunda parte da obra, denominada "O Ecletismo Metodológico”, aborda as especificidades dos métodos qualitativos utilizados, a análise da variação do valor percentual 
das principais rubricas de despesa que compõem a estrutura do orçamento familiar em Portugal (Continente), entre 1967 e 2006, tal como a análise das listas de despesas aplicadas mensalmente a trinta famílias portuguesas, durante um ano, e a partir das quais a questão da relação entre a reflexividade e as práticas de consumo é aprofundada. Além dos retratos sociológicos realizados a partir de entrevistas biográficas (aplicadas em seis famílias) que permitiriam uma avaliação das suas potencialidades na operacionalização do habitus, e por meio das quais procura-se estabelecer uma relação entre os diferentes contextos de socialização (nível meso) e as práticas de consumo (nível micro). Objetivando identificar as mudanças ocorridas nas estruturas de consumo de Portugal por meio de dados dos Inquéritos às despesas familiares (IDF1) realizados pelo Instituto Nacional de Estatística (INE) entre 1967 a 2006, e enquadrar o cruzamento da pluralidade disposicional e da sociologia dos indivíduos atendo a quadros/ cenários de interação, assim como comparar as estruturas do orçamento das famílias portuguesas diante de famílias europeias, através de dados fornecidos pela Eurostat, referentes aos anos de 1999 a 2005, Cruz utiliza-se de uma abordagem teórico-metodológica que favorece uma articulação entre os níveis macro, meso e microssociais. Sua pesquisa caracteriza-se também pelo uso do processo de abdução, onde dedução e indução são contempladas simultaneamente.

Os resultados apresentados corroboram com a perti- nência da Teoria da Prática de Bourdieu na análise das práticas de consumo. A análise das listas de despesas enfatizou um conjunto de hipóteses clássicas que foram integradas nos estudos de caso, além de acentuar a importância relativa das diferentes rubricas na estrutura do orçamento familiar e enfatizar a influência que variáveis como o gênero, a idade, o capital escolar, o tipo de agregado e a fase do ciclo de vida familiar, o lugar de classe e o rendimento exercem ao nível das práticas de consumo. Este é concebido como expressão de um querer mais ou menos constrangido pelos deveres sociais (regras de prescrição), pelos saberes adquiridos (socializações múltiplas, contextos de interação, entre outros), e pelos poderes (econômico, cultural, relacional, entre outros). As mudanças ao nível das práticas de consumo são justificadas a partir de tensões e ambivalências na motivação, correspondentes a situações críticas que implicam uma gestão dos desejos, que põem em causa a segurança ontológica. São identificados agentes sociais que vivem tanto sob a égide do princípio de realidade quanto sob a égide do princípio do prazer na sociedade portuguesa.

Os retratos sociológicos elaborados correspondem à última etapa do percurso teórico e metodológico da tese, que privilegia a proposta bourdiana de compreender a prática através da prática. Partindo de uma sociologia do indivíduo, explanada por Lahire (1998), a autora considera que os estudos de caso potenciam o reconhecimento da pluralidade in- 
terna do ator social. Três entrevistas compreensivas foram realizadas com cada uma das seis famílias escolhidas (famílias do tipo indivíduo só), que possibilitaram o estabelecimento de uma relação mais direta entre as socializações múltiplas, os diferentes contextos de interação e as práticas de consumo, além de contemplar as questões de gênero.

A relevância dos contextos de socialização na incorporação das disposições foi confirmada. Afirmou-se também que a análise dos retratos e a relação que através deles foi possível estabelecer entre as práticas de consumo e os diversos contextos de socialização e de interação confirmam a tese do ator plural. Nos retratos sociológicos, ainda que de modo diverso, foi possível identificar a influência que os contextos e as trajetórias de vida exercem na incorporação de disposições contraditórias.

Na terceira parte da obra as conclusões são apresentadas. A autora atenta também para determinados pontos críticos e limitações na análise das práticas de consumo. Alguns aspectos muito relevantes para a compreensão das práticas de consumo testados em sua investigação são destacados por Isabel Cruz.

Entre as suas conclusões, podemos ressaltar que as escolhas de consumo são condicionadas pelas disposições incorporadas e o desejo corresponde à satisfação da necessidade. Apesar disso, os condicionalismos das estruturas não anulam inteiramente a capacidade criativa dos agentes, que continuamente criam e recriam o significado simbólico dos objetos, realçando a subjetividade que caracteriza a sociedade de consumo. Atenta para a existência de uma tensão entre a capacidade do indivíduo recorrer aos bens de consumo para se singularizar e o condicionamento dos seus gostos pela posição social. Reconhece o efeito que o grau de urbanização exerce ao nível das práticas de consumo. Observa que o consumo depende da oferta de bens e serviços existentes. Foi comprovado que o aumento do nível de desenvolvimento socioeconômico se repercute numa maior autonomia do gosto face às condições materiais objetivas. Reafirma que o rendimento por si só não explica a estruturação do orçamento familiar de diferentes categorias sociais. As relações sociais são tidas como produtoras da estrutura de consumo dos diferentes grupos sociais, através das necessidades e práticas sociais. O consumo aqui explica-se pelo nível de vida, noção que significa poder de compra, além de medir o grau de integração na vida social e traduzir um conjunto de necessidades específicas e de consumos diferenciados. O caráter determinante da cultura nas escolhas de consumo é reforçado. No que diz respeito à estrutura do orçamento familiar, sua evolução reflete um aumento do bem-estar, nítido através da diminuição das despesas com alimentação e com vestuário e calçado e de um aumento dos valores relativos à habitação, aos transportes, à cultura e lazer e às comunicações. A ideia de que a subjetividade dos consumidores está repleta de esco- 
lhas de consumo e que a proximidade entre emergência e fim do desejo promovem essa mesma subjetividade é fortalecida. Sobre as entrevistas biográficas, sua realização possibilitou a caracterização da pertença familiar, das socializações múltiplas e dos contextos de interação ao nível familiar, escolar, laboral, amical e de lazer. A hipótese que estabelece uma relação de condicionamento entre a multiplicidade de processos de socialização, que se desenvolvem em diferentes contextos culturais, políticos e de interação e a incorporação do habitus é comprovada. A autonomia relativa da cultura é afirmada e a autora aponta a necessidade de reelaborar o conceito de capital cultural. O consumo é concebido como expressão de um querer mais ou menos constrangido pelos saberes adquiridos, pelos deveres sociais e pelos poderes. Já finalizando, enfatiza que muitas destas proposições conclusivas se ancoram num estudo de caso, de pendor qualitativo, limitação que não desconsidera que a investigação que embasa este trabalho constitui um passo que abre novas perspectivas para a Sociologia do Consumo, especificamente, mas não restritamente, em Portugal.

\section{REFERÊNCIAS BIBLIOGRÁFICAS:}

CRUZ, Isabel Maria Fernandes da Silva. Entre Estruturas e Agentes: padrões e práticas de consumo em Portugal Continental. Porto, Edições Afrontamento, 2013. 